\title{
A CONSCIENTIZAÇÃO PARA EDUCAÇÃO E PLANEJAMENTO DE SOLTURA DE AVES SILVESTRES APLICADOS À POPULAÇÃO DO BAIRRO DO JARDIM CUMBICA, MUNICÍPIO DE GUARULHOS-SP
}

\author{
Cristiano de Sousa Barriento, Solange Duarte
}

\section{RESUMO:}

O presente trabalho visa conscientizar e sensibilizar a população do Bairro do Jardim Cumbica, município de Guarulhos - SP referente aos malefícios do tráfico de aves silvestres, mostrar os impactos que podem ser causados no eco sistema, as possíveis doenças, e os reflexos negativos na questão sócio ambiental, na consequência da pratica na criação das aves silvestres, apresentar as principais aves Brasileira, traficadas no Brasil e para outros países do mundo, apontar também a quantia de dinheiro sujo gerado com esse tráfico, onde acaba incentivando e estimulando outras praticas ilegais como tráfico de drogas e armas, onde esperamos realmente conscientizar uma parcela da população de todos os possíveis crimes causados com o tráfico dos pássaros silvestres.

\section{ABSTRACT:}

The present work aims to raise awareness and sensitize the population of the Garden District Jardim Cumbica, Guarulhos city-SP regarding the dangers of trafficking of wild birds, to show the impacts that may be caused in the ecosystem, possible diseases, and the negative impact on the issue environmental partner, the result of practice in the creation of wild birds, presenting the main Brazilian birds, trafficked in Brazil end other countries, pointing also the amount of dirty money generated by this traffic, where it ends by encouraging and stimulating other illegal practices such as trafficking drugs end weapons, where we expect to actually realize a portion of the population of all possible crimes caused the trafficking of wild birds. 
Monografias Ambientais

(e-ISSN: 2236-1308)

REMOANFSM

\section{INTRODUÇÃO}

Tráfico de pássaros silvestres há muito tempo vem destruindo a nossa flora e fauna causando um gigantesco impacto em todo ecossistema, pratica essa causada pela atividade humana, e que pode ser conscientizada através da educação ambiental (www.wwf.org.br).

O conceito de "tráfico de animais silvestres": Tráfico é o comércio ilegal. Traficar animais significa capturá-los na natureza, prendê-los e vendê-los com o objetivo de ganhar dinheiro. Se participarmos disso, estamos contribuindo para o tráfico de animais. Acredita-se que o comércio ilegal de animais movimente cerca de 10 bilhões de dólares por ano em todo o mundo. Só o tráfico de drogas e armas é maior (www.ecodebate.com.br).

O conceito de "animal silvestre" Animal silvestre não é o doméstico. O doméstico já está acostumado a viver perto das pessoas, como os gatos, cachorros, galinhas e porcos, entre outros. Já o animal silvestre foi tirado da natureza e reage à presença do ser humano. Por essa razão, tem dificuldades para crescer e se reproduzir em cativeiro. O papagaio, a arara, o mico e o jabuti, ao contrário do que muitos pensam, são animais silvestres (www.wwf.org.br).

É importante mencionar que o Brasil abriga uma das mais diversas avifaunas do mundo, com o número de espécies estimado em mais de 1.690 (CBRO, 2003; IUCN, 2004; NatureServe, 2004). Isto equivale à aproximadamente $57 \%$ das espécies de aves registradas em toda América do Sul. Mais de $10 \%$ dessas espécies são endêmicas ao Brasil, fazendo deste país um dos mais importantes para investimentos em conservação (Sick, 1993).

As intervenções humanas afetaram, significativamente, as espécies de aves que habitam os ecossistemas naturais brasileiros. A resposta das aves à essas alterações varia desde aquelas que se beneficiaram com as alterações do habitat e aumentaram suas populações (p. ex., bem-te-vi [Pitangus sulphuratus]), até aquelas que foram extintas da natureza (p. ex., mutum-do-nordeste [Mitu mitu] e arara-azul-pequena [Anodorhynchus glaucus]). Na região neotropical, o Brasil é o país com o maior número de espécies de aves ameaçadas (Collar ET al., 1997).

Esse trabalho também analisou a distribuição das aves brasileiras e o número e distribuição das espécies de aves ameaçadas. Dessa forma Discutir as principais ameaças do presente e do futuro, e apresentamos um panorama das principais iniciativas de conservação e pesquisa. Finalmente, ressaltamos a necessidade de um programa integrado para a preservação pesquisa e soltura das espécies de aves ameaçadas no Brasil. 
O Brasil tem muitas espécies migrantes (61\%) vêm do hemisfério norte e são aves aquáticas que migram por longas distâncias e se congregam, sazonalmente, ao longo da costa ou nas grandes bacias de drenagem. Devido à colaboração internacional e a um sistema de anilhamento bem desenvolvido, esses migrantes têm sido bem estudados por pesquisadores e cientistas interessados no assunto. Em contraste, pouco se sabe a respeito das rotas migratórias e da distribuição, dentro do Brasil, de migrantes terrestres do norte, tais como o sabiánortemericano (Catharus fuscescens) e o sabiá-de-óculos (Catharus ustulatus) (Remsen, 2001). As espécies migratórias do sul representam 39\% das espécies migrantes.

Essas incluem a maria-preta-do-sul (Knipolegus hudsoni), com distribuição de inverno sualmente concentrada no sul do Brasil, mas cujos movimentos e história natural são comparativamente menos estudados que aqueles migrantes do norte (Sick, 1993).

O Brasil é um dos países do mundo que mais exporta animais silvestres ilegalmente é um negócio que movimenta mais de 1 bilhão de dólares e comercializa cerca de 12 milhões de animais anualmente. Uma das maiores ameaças à natureza .Acredita-se que o comércio ilegal de animais movimente cerca de 10 bilhões de dólares por ano em todo o mundo. Só o tráfico de drogas e armas é maior.

Todos os seres vivos dependem da natureza para sobreviver, pois é dela que obtemos desde alimentos até remédios. Os animais são parte fundamental da cadeia. Se forem extintos ou se tornarem raros, comprometem todo o equilíbrio da natureza. É importante enfatizar que há uma relação entre o tráfico nacional e o internacional: o Brasil possui um grande comércio interno de animais, que sustenta os traficantes que agem no país e servem como intermediários para os traficantes internacionais. Se o tráfico interno diminuir, o número de animais brasileiros levados para o exterior também será menor.

\section{METODOLOGIA}

Para desenvolver esse projeto, foram pesquisados as bibliografias dos principais conhecedores do tema "Tráfico de pássaros e animais silvestres", e também trabalhos de defensores e idealizadores na prevenção de animais silvestres. Foi realizada visitas técnicas para conhecimento de criação e recuperação de pássaros silvestres, através de um sistema chamado de quarentena que prepara os pássaros para futura soltura em seu habitat natural, pois esse tipo de 
Monografias Ambientais

(e-ISSN: 2236-1308)

REMOANFSM

soltura requer um estudo minucioso do local pois a introdução desses pássaros de nenhuma forma poderá trazer algum tipo de impacto no local, o trabalho também fez o uso de informações em paginas da internet de ONGs não governamentais.

\section{RESULTADOS ESPERADOS}

Através dessa proposta de trabalho esperamos conscientizar a população da região onde o projeto foca sobre a criação ilegal de pássaros silvestres e reduzir a captura, comercio e criação de pássaros silvestres e recuperar os pássaros já capturados e hoje criadas em residências ou prezo por autoridades fiscalizadoras, através de um processo de quarentena recuperalos para soltura em seu habitat natural.

\section{REFERÊNCIAS BIBLIOGRÁFICAS}

FRISCH, JD Aves Brasileiras 1989 São Paulo, Dalgas Ecoltec Ecologia Técnica 351p.

DUNNING J.S South American Birds 1989

SICK, H Birds in Brasil 1993

GRANTSAU, R. Os Beija-flores 1988

SICK, H . Ornitologia Brasileira. 1997 Rio de Janeiro, Ed Fronteira. 912p.

Meio Ambiente Agora 2011 disponível em:

(http://meioambienteagora.com.br) Acesso em: 4 de Agosto de 2011

Natureba vegetarismo 2011 disponível em:

http://www.natureba.com.br/trafico-animais-silvestres.htm

Acesso em: 03 de Agosto de 2011

O que é um animal silvestre 2011 disponível em:

http://www.wwf.org.br/informacoes/questoes_ambientais/animais_silvestres/

Acesso em: 3 de Agosto de 2011

http://www.ibama.gov.br/fauna-silvestre/wp-content/files

Acesso em: 9 de Agosto de 2011 